\title{
Insecticide resistance in Culex quinquefasciatus from Zanzibar: implications for vector control programmes
}

Christopher M Jones ${ }^{1 \dagger}$, Camille Machin ${ }^{1 \dagger}$, Khalfan Mohammed ${ }^{2}$, Silas Majambere ${ }^{1,3}$, Abdullah S Ali ${ }^{4}$, Bakari O Khatib ${ }^{4}$, Juma Mcha ${ }^{4}$, Hilary Ranson ${ }^{1}$ and Louise A Kelly-Hope ${ }^{1 *}$

\begin{abstract}
Background: Zanzibar has a long history of lymphatic filariasis (LF) caused by the filarial parasite Wuchereria bancrofti, and transmitted by the mosquito Culex quinquefasciatus Say. The LF Programme in Zanzibar has successfully implemented mass drug administration (MDA) to interrupt transmission, and is now in the elimination phase. Monitoring infections in mosquitoes, and assessing the potential role of interventions such as vector control, is important in case the disease re-emerges as a public health problem. Here, we examine Culex mosquito species from the two main islands to detect $W$. bancrofti infection and to determine levels of susceptibility to the insecticides used for vector control.

Methods: Culex mosquitoes collected during routine catches in Vitongoji, Pemba Island, and Makadara, Unguja Island were tested for $W$. bancrofti infection using PCR. Insecticide bioassays on Culex mosquitoes were performed to determine susceptibility to permethrin, deltamethrin, lambda-cyhalothrin, DDT and bendiocarb. Additional synergism assays with piperonyl butoxide (PBO) were used for lambda-cyhalothrin. Pyrosequencing was used to determine the $k d r$ genotype and sequencing of the mitochondrial cytochrome oxidase I (mtCOI) subunit performed to identify ambiguous Culex species.
\end{abstract}

Results: None of the wild-caught Culex mosquitoes analysed were found to be positive for W. bancrofti. High frequencies of resistance to all insecticides were found in Wete, Pemba Island, whereas Culex from the nearby site of Tibirinzi (Pemba) and in Kilimani, Unguja Island remained relatively susceptible. Species identification confirmed that mosquitoes from Wete were Culex quinquefasciatus. The majority of the Culex collected from Tibirinzi and all from Kilimani could not be identified to species by molecular assays. Two alternative $k d r$ alleles, both resulting in a L1014F substitution were detected in CX. quinquefasciatus from Wete with no homozygote susceptible detected. Metabolic resistance to pyrethroids was also implicated by PBO synergism assays.

Conclusions: Results from the xenomonitoring are encouraging for the LF programme in Zanzibar. However, the high levels of pyrethroid resistance found in the principle LF vector in Pemba Island will need to be taken into consideration if vector control is to be implemented as part of the elimination programme.

Keywords: Lymphatic filariasis, Malaria, Vector control, Insecticide resistance, Zanzibar

\footnotetext{
* Correspondence: I.kelly-hope@liverpool.ac.uk

+ Contributed equally

'Liverpool School of Tropical Medicine, Pembroke Place, Liverpool L3 5QA,

UK

Full list of author information is available at the end of the article
} 


\section{Background}

The Zanzibar archipelago has a long history of lymphatic filariasis (LF), a disabling mosquito-borne disease caused by the filarial parasite Wuchereria bancrofti [1-6]. The mosquito species Culex quinquefasciatus Say, is the most important vector of $W$. bancrofti in the East African coast and the islands of the Indian Ocean, including Zanzibar, however Anopheles gambiae s.l and An. funestus also play a role in selected areas [7-10]. Cx. quinquefasciatus is a member of the Culex pipiens complex Linnaeus and one of the main subspecies found in Africa [11-13]. It is efficient at maintaining low levels of microfilariae (Mf) within a population, highly anthropophilic, and predominately bites at night. This species is a major biting nuisance, particularly in urban areas where it thrives in wet pit latrines, cess pits, blocked open drains, and polluted puddles. In Zanzibar, W. bancrofti Mf rates have ranged from $0.3 \%$ to $20.3 \%$ in Culex species $[1-3,6,7,14]$, unpublished data.

LF has historically been a significant public health problem in Zanzibar, particularly on the main islands of Unguja and Pemba, where human W. bancrofti Mf rates ranged from $3 \%$ to $49 \%$, and clinical manifestations such as hydrocele and lymphodema (elephantiasis) were common [1-6]. The LF programme was established in 1994 and a mass drug administration (MDA) campaign initiated to treat all the eligible population in $2001[4,5]$ following the launch of the Global Programme to Eliminate LF (GPELF) by the World Health Organization (WHO) [15]. Zanzibar was one of the first places in the United Republic of Tanzania and sub-Saharan Africa to target LF elimination and implement six consecutive rounds of annual MDA using a combination of ivermectin and albendazole with the aim of interrupting $W$. bancrofti transmission $[4,5]$. It achieved $>80 \% \mathrm{MDA}$ coverage with a reduction in LF prevalence to $0 \% \mathrm{Mf}$ rate, and has potentially reached its goal of elimination. However, with no systematic post-MDA surveillance in place it is not possible to fully determine if disease transmission has been completely interrupted. Xenomonitoring presents a cost-effective way of monitoring LF within a population [16-18] and opportunities to collect and examine mosquitoes within existing vector surveillance programmes should be utilised where possible.

Assessing the additional impact of vector control and monitoring insecticide resistance is also important in Zanzibar as there has recently been extensive scale up of indoor residual spraying (IRS) and distribution of insecticide treated/long lasting nets (ITNs/LLINs) as part of the Zanzibar Malaria Control Programme (ZMCP), supported by the Presidents Malaria Initiative (PMI) and other international donors [19,20]. Zanzibar is one of the first places in Tanzania and sub-Saharan
Africa to be targeted for malaria elimination, and since 2006 has conducted five rounds of IRS with the pyrethroid insecticide lambda-cyhalothrin [19]. More than 90\% IRS coverage has been achieved, protecting over one million people. Free ITNs/LLINs have also been distributed and it is estimated that $>75 \%$ of households own at least one ITN/LLIN [19]. It is possible that Culex populations may be affected by the wide use of insecticides and developed resistance even though these species were not being targeted. There is precedent for this in Zanzibar where previous vector control using organophosphate and organochlorine insecticides have been carried out in the 1950s-80s [21,22] and resistance in Culex and Anopheles species detected [23-26].

Widespread resistance could prove problematic if LF were to re-emerge or be re-introduced from the endemic mainland of Tanzania or Kenya $[9,10]$, and supplementary vector control using insecticides were required in addition to MDA [15]. Insecticide resistance in Culex species could also impact on the malaria elimination programme if communities perceive a reduced efficacy of IRS and ITN/LLINs and usage rates decline. Given the post-MDA phase and importance of surveillance in Zanzibar, this study aimed to examine Culex species to detect $W$. bancrofti infection from routine entomological collections and to determine levels of susceptibility to insecticides used in vector control programmes.

\section{Methods}

\section{Detection of Wuchereria bancrofti}

Blood-fed mosquitoes were collected from the inside of houses using pyrethroid spray catches (PSC) with permission from the village chief and the head of each household. The PSCs are part of routine entomological monitoring by the ZMCP which are carried out every 2 to 4 weeks and collections were made between 0530 and 0930 hours during April-May 2011. For the purpose of this study, only female culicines were used with the remaining males being discarded. Collections were conducted from the following sites: Vitongoji (Pemba) $5^{\circ}$ 12'42" South, $39^{\circ} 49^{\prime} 51^{\prime \prime}$ East, Makadara (Unguja) $6^{\circ}$ 09'93" South, $39^{\circ} 11^{\prime} 54$ " East (Figure 1).

Genomic DNA (gDNA) was extracted from 226 individual mosquitoes collected from the PSCs using the DNeasy kit (QIAGEN) following the manufacturer's instructions. The presence or absence of W. bancrofti in Culex mosquitoes was detected using the PCR diagnostic described by Ramzy et al. [27]. gDNA from five individual mosquitoes were pooled according to the respective sites and screened. If the pooled sample yielded a positive result, mosquitoes from that pool were screened to isolate the $W$. bancrofti-positive individual. To confirm any putative positive samples, a melt- 


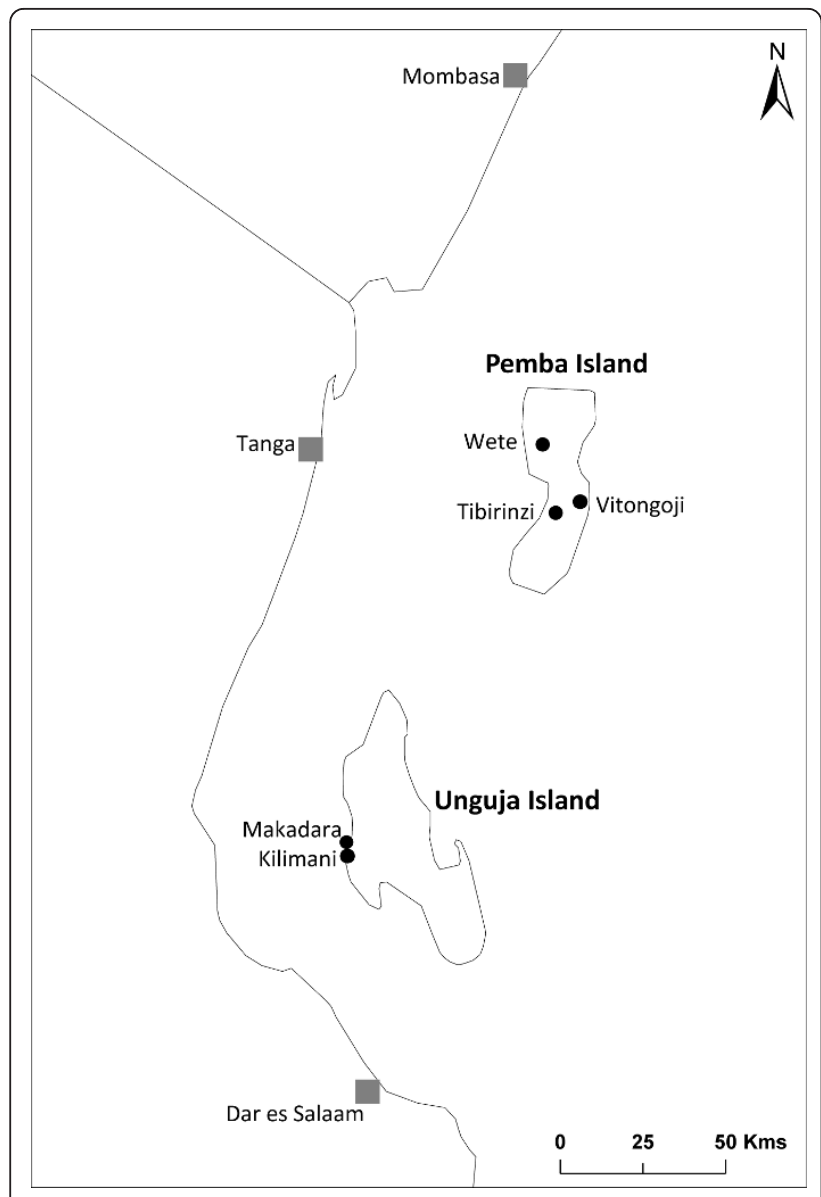

Figure 1 Study sites on Unguja and Pemba Islands, Zanzibar.

curve analysis was conducted using the diagnostic primers from Ramzy et al. [27]. Melt curve analysis is a quantitative PCR (qPCR) assay which determines the specificity of amplified PCR products according to their unique melting temperatures $\left(\mathrm{T}_{\mathrm{m}}\right)$. The $188 \mathrm{bp}$ amplified product was detected using the Brilliant III UltraFast SYBR ${ }^{\circledR}$ Green Master Mix (Agilent Technologies) on the Stratagene Mx3005P (Agilent Technologies). Real-time PCR reactions were run following a thermal profile of 3 mins at $95^{\circ} \mathrm{C}$ followed by 40 cycles of $10 \mathrm{~s}$ at $95^{\circ} \mathrm{C}$ and $10 \mathrm{~s}$ at $60^{\circ} \mathrm{C}$. Immediately following amplification, melt curves were generated by increasing the temperature incrementally from $55^{\circ} \mathrm{C}$ to $95^{\circ} \mathrm{C}$ while SYBR $^{\circledR}$ Green is continually detected. The presence of a single homogeneous peak in the melt curve plot (temperature versus first derivative of raw fluorescence) is indicative of specific amplification (characteristic $\mathrm{T}_{\mathrm{m}}$ ).

\section{Culex insecticide susceptibility assays}

Culex larvae (L1 to L4) were collected from two sites on Pemba (Wete: $5^{\circ} 3^{\prime} 21^{\prime \prime}$ South, $39^{\circ} 43^{\prime} 45^{\prime}$ East; Tibirinzi: $5^{\circ} 14^{\prime} 31^{\prime \prime}$ South, $39^{\circ} 45^{\prime} 53^{\prime \prime}$ East) and from one site on
Unguja (Kilimani - $6^{\circ} 10^{\prime} 5^{\prime}$ South, $39^{\circ} 12^{\prime} 49^{\prime}$ East) (Figure 1). All larvae were transported to the insectaries of ZMCP for adult rearing.

Approximately one-hundred non-blood-fed female 2-5 day old adults were exposed to the following WHO insecticide-treated papers for one-hour: permethrin $(0.75 \%)$, deltamethrin (0.05\%), lambda-cyhalothrin $(0.05 \%)$, DDT $(4 \%)$ and bendiocarb $(0.1 \%)$. The percentage mosquito mortality was recorded 24 hours later. Control assays were performed throughout the experiment with a minimum of 25 mosquitoes exposed to non-insecticide treated papers.

In order to determine the level of lambda-cyhalothrin resistance, time-mortality response assays were conducted from Wete (Pemba) and Kilimani (Unguja). Approximately one-hundred Culex mosquitoes were exposed to lambda-cyhalothrin $(0.05 \%)$ treated papers for six time points from Wete $(30,60,90,120,240$ and 360 mins) and four time points from Kilimani (15, 30, 45 and 60 mins). Control assays using non-insecticide treated papers were conducted throughout.

\section{PBO synergist assays}

To investigate the potential involvement of metabolic resistance in Culex from Wete, mosquitoes were preexposed to the synergist $\mathrm{PBO}$ (piperonyl butoxide); a known inhibitor of P450 and esterase activity. Approximately 75 female mosquitoes were pre-exposed to $4 \%$ PBO-treated papers for one-hour and immediately exposed to lambda-cyhalothrin $(0.05 \%)$ for a further hour. Mortality was scored 24 hours later and any synergism compared with mortality from assays conducted without pre-exposure to PBO (described above).

\section{PCR identification of Culex quinquefasciatus}

$C x$. quinquefasciatus is a member of the $C x$. pipiens species complex and is generally assumed to predominate Culex mosquitoes from Zanzibar [10-14]. The PCR diagnostic described by Smith and Fonseca [28] uses a series of diagnostic primers to discriminate four members of the Culex pipiens complex plus $C x$. torrentium and $C x$. pervigilans based on single nucleotide polymorphisms (SNPs) in an intron of the acetylcholinesterase-2 (ace-2) gene. The primers ACEquin (5'-CCTTCTTGAAT GGCTGTGGCA-3') and B1246 (5'-TGGAGCCTCCTC TTCACGG-3') amplify a 274 bp diagnostic fragment of $C x$. quinquefasciatus. In this study, $1 \mu \mathrm{l}$ of gDNA from 19-24 individuals from Wete (Pemba), Tibirinzi (Pemba) and Kilimani (Unguja) were added to $20 \mu \mathrm{l} \mathrm{PCR} \mathrm{reac-}$ tions using the $C x$. quinquefasciatus specific primers under the following thermal cycling conditions: $95^{\circ} \mathrm{C}$ for 2 mins, followed by 35 cycles of $95^{\circ} \mathrm{C}$ for $30 \mathrm{~s}, 55^{\circ} \mathrm{C}$ for $30 \mathrm{~s}$ and $72^{\circ} \mathrm{C}$ for $16 \mathrm{~s}$ with a final extension step of $72^{\circ}$ 
C for 2 mins. Individuals which failed to amplify after two attempts were classed as 'other' species.

To confirm the presence of additional Culex species on Zanzibar, $1 \mu \mathrm{l}$ of gDNA from a subset of $C x$. quinquefasciatus positive and negative samples was used to amplify a $\sim 800$ bp region of the mitochondrial cytochrome oxidase I (mtCOI) sequence. $\mathrm{mtCOI}$ is a common molecular marker for cryptic species complexes in insects and the universal primers used to amplify this region have been described elsewhere [29]. The PCR product was purified (QIAquick PCR-Purification kit; QIAGEN) and sequenced in both the forward and reverse direction using the reaction PCR primers by Macrogen Inc. (Amsterdam, Netherlands). Sequences were analysed and aligned in CodonCode Aligner (CodonCode Corporation, Dedham, MA) and compared with other Culicine mtCOI sequences from an independent study at LSTM (D. Weetman pers. communication). Unique sequences were submitted to GenBank.

\section{Target-site resistance mutations}

Genomic DNA was extracted from mosquitoes exposed to lamda-cyhalothrin $(0.05 \%)$ for 240 mins from Wete using either the DNeasy extraction kit (QIAGEN) or the 'Livak' protocol described previously [30]. For the Livak method, individual mosquitoes were homogenised in $100 \mu \mathrm{l}$ of pre-heated $\left(65^{\circ} \mathrm{C}\right)$ Livak buffer [30] and samples incubated at $65^{\circ} \mathrm{C}$ for $30 \mathrm{~min}$. Potassium acetate was added (14 $\mu \mathrm{l}$ of $8 \mathrm{M}$ stock) and the samples incubated on ice for $30 \mathrm{~min}$. The supernatant was collected following centrifugation (13,200 rpm for $20 \mathrm{~min}$ ) and mixed with $100 \%$ ethanol at 13,200 rpm for $15 \mathrm{~min}$. The DNA pellet was washed in $70 \%$ ethanol, air-dried for 1 $\mathrm{hr}$ and re-suspended in $100 \mu \mathrm{l}$ of sterile distilled water.

A pyrosequencing assay was used to determine the genotype at position 1014 ( $k d r$ site) in the sodium channel [31]. The assay detects one of three potential nucleotides $(\mathrm{A} / \mathrm{T} / \mathrm{C})$ at the third position in the 1014 codon [31]. In brief, a 154 bp region was PCR-amplified with forward and biotinylated reverse primers (Table 1). The sequence analysed to detect the genotype at 1014 was 5'-TT[A/C/T] GTCGTGAGTATTCCAG-3'. Pyrosequencing reactions were performed using the PyroMark Gold Q96 Reagents Kit (QIAGEN) on the PyroMark

Table 1 Detection of $W$. bancrofti in Culex spp. caught from PSC in Zanzibar

\begin{tabular}{cccc}
\hline & & \multicolumn{2}{c}{ W. bancrofti detection* } \\
\hline Island & Site & Positive & Negative \\
\hline Pemba & Vitongoji & 0 & 150 \\
\hline Unguja & Makadara & 0 & 76 \\
\hline
\end{tabular}

*Presence or absence of $W$. bancrofti determined using PCR diagnostic described Ramzy et al. (1997)
Q96 system (QIAGEN). The relative heights of the bioluminescence peaks for each nucleotide were used to genotype each individual [31].

Resistance to carbamates and organophosphates in Anopheles and Culex mosquitoes is associated with a mutation (glycine to serine at position 119 or G119S) in the ace-1 gene encoding acetylcholinesterase (AChE) [32]. The presence of G119S in Culex mosquitoes from Zanzibar was determined using the Restriction Fragment Length Polymorphism (RFLP) assay described by Weill et al. [33]. In brief, gDNA from 20 individuals from Wete (Pemba) and Kilimani (Unguja) was added to a 20 $\mu \mathrm{l}$ PCR reaction using the degenerate Moustdir 1 and Moustrev1 primers which amplify a 194 bp fragment of ace-1. PCR products were digested with the AluI restriction enzyme and run on a $1.5 \%$ agarose gel.

\section{Statistical analysis}

Exact 95\% confidence intervals for knockdown and mortality data from discriminatory dose bioassays were calculated in $\mathrm{R}$ for Windows version 2.2. Time response curves and $\mathrm{LT}_{50}$ and $\mathrm{LT}_{90}$ values were generated using Probit analysis in XL STAT.

\section{Results}

\section{Detection of $W$. bancrofti from Zanzibar}

A total of 226 mosquitoes caught by PSC from Zanzibar (150 from Vitongoji (Pemba) and 76 from Makadara (Unguja) were examined for the presence of W. bancrofti (Table 1). None of the wild-caught Culex mosquitoes analysed were found to be positive for W. bancrofti. In a separate study conducted in parallel with the data presented here, $W$. bancrofti infected Culex were identified from Dar es Salaam by both the standard PCR diagnostic [27] and melt-curve analysis (Figure 2), confirming that the sensitivity of both assays is sufficiently reliable for detecting $W$. bancrofti from wildcaught mosquitoes.

\section{Insecticide resistance bioassays}

Culex mosquitoes from Wete (Pemba) were resistant to all insecticides tested (Figure 3a). Low mortality levels were obtained after exposure of Culex from Wete to pyrethroid or DDT (deltamethrin $=19.4 \%, 95 \%$ CI: $12.3-$ 28.4\%; permethrin $=14.0 \%$, 95\% CI: 7.9-22.4\%; lambdacyhalothrin $=24.0 \%, 95 \%$ CI: $16.0-33.6 \%$, DDT $=3.2 \%$, 95\% CI: $0.7-9.1 \%)$. Moderate mortality rates were observed after exposure to the carbamate, bendiocarb (52.4\%, 95\% CI: 42.4\%-62.4\%). In contrast to Wete, mosquitoes from the other site tested on Pemba, Tibirinzi, were almost fully susceptible to all three pyrethroids (Figure 3c). Although resistance to DDT was detected from Tibirinzi, this was at a lower level than Wete (46.0\%, 95\% CI: 33.4-59.1). Culex populations from 

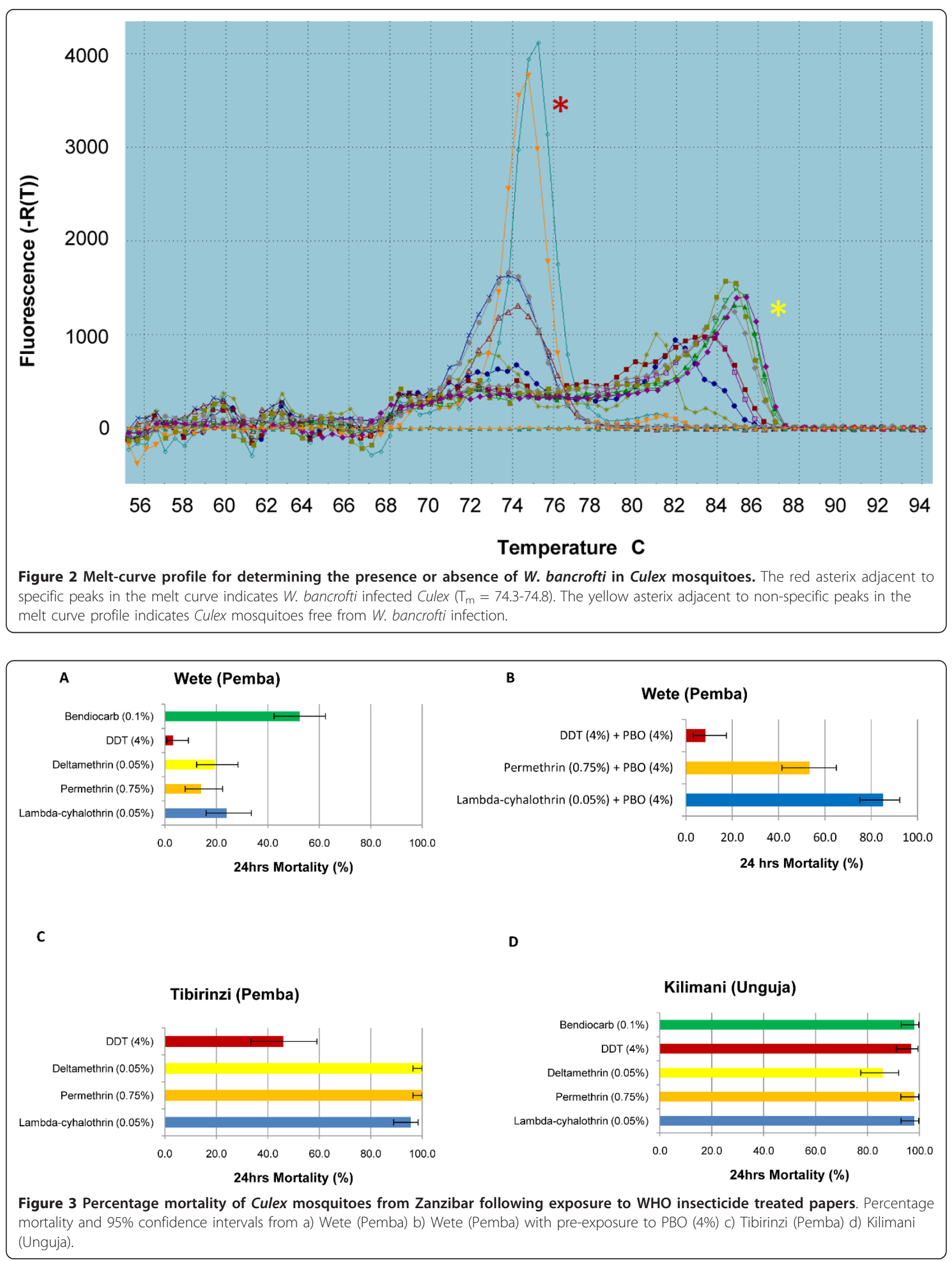
Unguja were largely susceptible to all insecticides with only deltamethrin giving any detectable level of resistance (86\% mortality, 95\% CI: 77.4-92.0\%) (Figure 3d).

Insecticide resistant mosquitoes from Wete on Pemba were pre-exposed to the synergist PBO (4\%) for onehour before exposure to lambda-cyhalothrin $(0.05 \%)$, permethrin $(0.75 \%)$ and DDT (4\%). Synergism was evident against the pyrethroids with mortality rising to $53.3 \%$ and $85.1 \%$ for permethrin and lambda-cyhalothrin respectively while there was no evidence of synergism with DDT (8.5\%, 95\% CI: 3.2-17.5\%) (Figure 3b). This suggests that metabolic (e.g. P450-mediated) resistance may contribute to the resistance phenotype but is not the sole mechanism in Culex from Wete.

Assays to determine the $\mathrm{LT}_{50}$ (lethal time taken to kill approximately $50 \%$ of mosquitoes) for lambda-cyhalothrin were performed for Culex from Wete and Kilimani. Generation of probit curves for Kilimani Culex were rejected due to the relatively high levels of susceptibility to lambda-cyhalothrin in this population ( $\mathrm{P}>$ 0.05). However, the estimated $\mathrm{LT}_{50}$ for the Wete population was $199.4 \mathrm{mins}$ ( $95 \mathrm{CI} \%=183.3-217.8 \mathrm{mins}$ ), demonstrating the extremely high levels of resistance to this pyrethroid.

\section{Molecular determination of Culex species}

Confirmation of $C x$. quinquefasciatus from each of the insecticide resistance study sites on Zanzibar was performed using the method described by Smith and Fonseca [28]. Eighty-four percent of Culex from Wete on Pemba Island $(\mathrm{N}=19)$ were confirmed as $C x$. quinquefasciatus. In contrast, only $13 \%$ and $0 \%$ of the mosquitoes from Tibirinzi (Pemba) $(\mathrm{N}=24)$ and Kilimani (Unguja) $(\mathrm{N}=20)$ respectively were identified as $C x$. quinquefasciatus using this molecular diagnostic (Figure 4). A $760 \mathrm{bp}$ region of the mtCOI marker from a subset of $C x$. quinquefasciatus and unidentified Culex spp. was therefore compared with other available Culicine sequences. All samples sequenced from Wete had a single mtCOI haplotype (GenBank acc. no. JN990140), which was consistent with other members of the $C x$. pipiens species complex. Seventy-one polymorphic sites existed between the population from Wete and four distinct haplotypes that were found in Tibirinzi (GenBank acc. no's JN990141-JN990144). The Tibirinzi haplotypes clustered into a separate group when compared with other Culicine mtCOI sequences (D. Weetman pers. communication) and therefore could not be identified to species level.

\section{Frequency of target-site resistance mutations}

Mosquitoes from Wete were collected either (i) following exposure to lambda-cyhalothrin $(0.05 \%)$ for 240 minutes (dead or alive) or (ii) without exposure to insecticide treatment, for genotyping at the $1014 k d r$ position in the voltage-gated sodium channel. The wild-type allele (TTA) was absent from all samples genotyped using the pyrosequencing assay. Two variant substitutions at the third coding position of 1014 were identified, both of which result in an amino acid change from leucine to phenylalanine (L1014F), TTT and TTC. Homozygous $\mathrm{T} / \mathrm{T}$ individuals predominated in this population (genotype frequency $=0.73$ ) with heterozygote $\mathrm{T} / \mathrm{C}$ and homozygous $\mathrm{C} / \mathrm{C}$ at lower levels (genotype frequencies $=0.23$ and 0.04 respectively). However, since all genotypes encode phenylalanine at 1014, the alternative codons are unlikely to have any impact on the phenotype. Indeed, there was no apparent difference in the frequency of each genotype between survivors and dead from insecticide treatment or between those unexposed (Table 2).

Twenty Culex mosquitoes were screened for the presence of the G119S mutation in the ace-1 gene from Wete and Kilimani. Three heterozygous individuals were detected from Wete (frequency of $119 \mathrm{~S}=0.08$ ) while no resistant genotypes were found in the samples

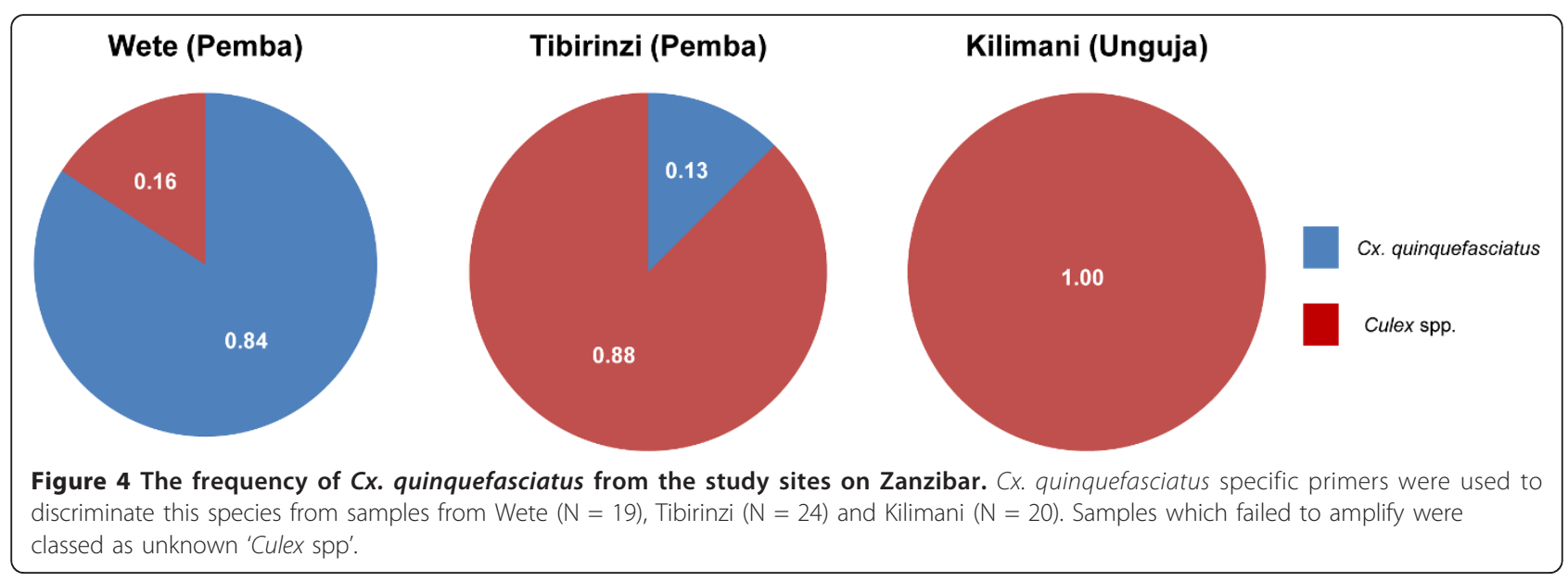


Table 2 Frequency of 1014 kdr genotypes in Culex mosquitoes from Wete with or without exposure to lambdacyhalothrin $(0$

\begin{tabular}{|c|c|c|c|c|c|c|c|}
\hline \multirow[b]{2}{*}{ Treatment } & \multirow[b]{2}{*}{ Phenotype } & \multirow[b]{2}{*}{$\mathbf{N}$} & \multirow[b]{2}{*}{$\mathrm{A} / \mathrm{A}$} & \multicolumn{4}{|c|}{ Genotype* } \\
\hline & & & & $\mathrm{A} / \mathrm{T}$ & $\mathrm{T} / \mathrm{T}$ & $\mathrm{C} / \mathrm{T}$ & $\mathrm{C} / \mathrm{C}$ \\
\hline \multirow[t]{2}{*}{ Lambda-cyhalothrin $(0.05 \%)^{\lambda}$} & Dead & 26 & 0 & 0 & $15(0.58)$ & $11(0.42)$ & 0 \\
\hline & Alive & 29 & 0 & 0 & $26(0.90)$ & $3(0.10)$ & 0 \\
\hline \multirow[t]{2}{*}{ Unexposed } & Control & 14 & 0 & 0 & $9(0.64)$ & $2(0.14)$ & $3(0.21)$ \\
\hline & Total & 69 & 0 & 0 & $50(0.73)$ & $16(0.23)$ & $3(0.04)$ \\
\hline
\end{tabular}

*1014 genotype at the third coding position determined using pyrosequencing

${ }^{\lambda}$ Following 240 minutes exposure to lambda-cyhalothrin (0.05\%)

screened from Kilimani suggesting insensitive acetylcholinesterase may play a partial role in the carbamate resistance observed from Wete.

\section{Discussion}

This study examining $W$. bancrofti infection in Culex species from the two main islands of Zanzibar in the post-MDA phase of the LF Programme (now incorporated into the Neglected Tropical Disease (NTD) Programme) [5], provides valuable information on the main vector. However, to fully confirm the interruption of LF transmission, it would be necessary to increase sample sizes significantly, and extend xenomonitoring activities over time and space in accordance with current recommendations [18], and with the support of national entomologists, scientists and vector control programmes.

Synergies between LF and malaria vector control activities are encouraged by WHO [34], and the Zanzibar NTD Programme is well placed to take advantage of the routine surveillance carried out for malaria by the ZMCP, where thousands of Culex mosquitoes are collected at sentinel sites each year. Systemic testing of $W$. bancrofti in Cx. quinquefasciatus may provide early warning signs of recrudescence or re-introduction from the endemic mainland where human travel is frequent [35], especially as there is evidence that antigen carriers may have re-emerged on the islands and PCR positive mosquitoes have been detected in other locations in recent years (unpublished observations). Systematic surveillance could help to target further interventions if required, including vector control.

The extent to which IRS and ITN/LLIN activities for malaria have played a role in reducing LF prevalence or maintaining $<25 \%$ Mf rates in Zanzibar is unclear. However, the concurrent scale up of malaria vector control with the sixth and final round of MDA for LF may well have increased the impact on $W$. bancrofti transmission at the time $[19,20,36,37]$. The use of IRS and ITN/ LLINs in other countries in Africa [38-40] and the Pacific [41-43] have been shown to be effective in reducing LF prevalence, however transmission was by Anopheles vectors, and predominately in rural areas.
Effective vector control of $C x$. quinquefasciatus in urban areas of Tanzania has been achieved through environmental improvement, larval source reduction, application of polystyrene beads and use of insecticides [8,11,44-48]. For example, previous studies in Zanzibar have shown significant reductions of $W$. bancrofti infection rates in both human and $C x$. quinquefasciatus by using polystyrene beads in wet pit latrines [7]. In Zanzibar and Dar es Salaam, larviciding with chlorpyrifos was used effectively in flooded pit latrine and septic tanks during the 1970s-80s, however resistance to this insecticide was detected after a number of years [23,24,44,49]. None of these methods are currently being employed in Zanzibar.

This is the first study we are aware of to document insecticide resistance levels in Culex species from Zanzibar in the last three decades. Organophosphate resistance has been previously reported in $C x$. quinquefasciatus from Zanzibar [23,24], and pyrethroid, organophosphate and carbamate resistance in $C x$. quinquefasciatus from Tanzania mainland [44,50,51]. Here, strong resistance to all insecticide classes tested were found in Cx. quinquefasciatus from Wete on Pemba Island, whereas relative susceptibility was found in the nearby site of Tibirinzi (Pemba) and in Kilimani on Unguja Island. Comparing resistance between these sites is not possible given the unexpected finding that the majority of Culex caught from Tibirinzi and Kilimani are apparently not members of the Cx. quinquefasciatus complex. Unfortunately, morphological identification was not performed on these species and hence their identity and behavioural patterns remain unknown. It is possible that these species do not enter houses, and are thus not affected by IRS, which may explain their lack of resistance.

The high levels of resistance in Cx. quinquefasciatus may be related to the current malaria control activities in Zanzibar. Two variants of the $k d r 1014 \mathrm{~F}$ allele were detected from all Culex sampled from Pemba, both of which result in a leucine to phenylalanine substitution at codon 1014. This substitution is strongly associated with pyrethroid and DDT resistance in An. gambiae s.l. 
[52]. The A-to-T mutation has been reported from different members of the $C x$. pipiens complex including pyrethroid resistant $C x$. quinquefasciatus from West and East Africa [50,53-55]. The second mutation, an A-to-C substitution, was found at a lower frequency from Wete and has been previously documented from $C x$. quinquefasciatus from Sri Lanka [31] but not from the African continent. The fixation of 1014 F in the Wete population and cross resistance with DDT, suggests that selection pressures have been acting against $k d r$ for some time.

The historical and extensive use of DDT in IRS during the 1950s-80s [21,22], local agricultural usages and/or extensive use of pyrethroids in malaria control $[52,56]$, could all feasibly play a role in selecting for $k d r$ in Culex from Pemba. The synergism with PBO however, indicates that other mechanisms, such as $\mathrm{P} 450$-mediated detoxification, may also be contributing to the observed resistance patterns. Whatever the mechanisms involved, the strong levels of pyrethroid resistance in $C x$. quinquefasciatus from Wete $\left(\mathrm{LT}_{50}=199.4 \mathrm{mins}\right)$ could have broader implications for the control of all vector-borne diseases on Pemba Island, particularly if it reduces community engagement in vector control programmes. Furthermore, the presence of bendiocarb resistance (52.4\% mortality) together with $119 \mathrm{~S}$ in ace-1 in Wete, albeit at a low frequency, means that switching to a carbamate-based vector control strategy, may not extensively suppress Culex from this area and indeed, potentially select for further resistance.

\section{Conclusion}

Insecticide resistance in Cx. quinquefasciatus is of concern for the NTD Programme if insecticide-based control methods are considered as an intervention in the future. However, this is unlikely in this setting given the effectiveness of the current drugs used for elimination [15]. Moreover, further rounds of MDA in combination with alternative vector control methods such as polystyrene beads may be more effective and practical if LF were to re-emerge as a public health problem in Zanzibar.

\footnotetext{
Acknowledgements

Thanks go to Dr Greg Devine from the Ifakara Health Institute, Tanzania, for introducing us to the study sites and assisting us in the field. We are grateful to Matthew Daley form the Liverpool School of Tropical Medicine (LSTM) and other members of the Zanzibar Malaria Control Programme (ZMCP) for their assistance in the field and laboratory, and also to Dr Dave Weetman (LSTM) for his advice on the mtCOI Culex spp. sequencing. Finally, we appreciate comments on the manuscript from Prof. Moses Bockarie (LSTM).

Funding

The study was supported by a grant from the Department for International Development (DFID) and GlaxoSmithKline (GSK) for research on the elimination of lymphatic filariasis.
}

\section{Author details}

1'Liverpool School of Tropical Medicine, Pembroke Place, Liverpool L3 5QA, UK. ${ }^{2}$ Ministry of Health and Social Welfare, Miazini, Zanzibar, Tanzania. ${ }^{3}$ Ifakara Health Institute, Kiko Avenue, Mikocheni, P.O. Box 78373 Dar es Salaam, Tanzania. ${ }^{4}$ Zanzibar National Malaria Control Programme,

M'kwerekwe Street, Ministry of Health and Social Welfare, Zanzibar, Tanzania.

\section{Authors' contributions}

LKH and HR conceived the study. CM, CMJ, KM, SM, BK, JM and AA carried out the field work. CM, CMJ and HR designed and performed the lab experiments. CM, CMJ, HR, and LKH analyzed the data, interpreted the results and wrote the first draft of the paper. All authors read and approved the final manuscript.

\section{Competing interests}

The authors declare that they have no competing interests.

Received: 17 March 2012 Accepted: 21 April 2012

Published: 21 April 2012

\section{References}

1. Mansfield-Aders W: Notes on malaria and filariasis in the Zanzibar Protectorate. Trans R Soc Trop Med Hyg 1927, 1:207-214.

2. McCarthy DD: Medical notes from Weti, Pemba. Trans $R$ Soc Trop Med Hyg 1930, 23:401-412.

3. Kilama WL, Swai ABM, Kihamia CM, Rwiza H: Bancroftian Filariasis in Zanzibar Zanzibar: Mimeographed Report, Ministry of Health; 1975.

4. Mohammed KA: Lymphatic filariasis in Zanzibar: epidemiology, elimination and impact. PhD Thesis University of Liverpool; 2009.

5. Mohammed KA, Molyneux DH, Albonico M, Rio F: Progress towards eliminating lymphatic filariasis in Zanzibar: a model programme. Trends Parasitol 2006, 22:340-344.

6. Pedersen EM, Kilama WL, Swai ABM, Kihamia CM, Rwiza H, Kisumku UM: Bancroftian filariasis on Pemba Island, Zanzibar, Tanzania: An update on the status in urban and semi-urban communities. Trop Med Intl Hith 1999, 4:295-301.

7. Maxwell CA, Curtis CF, Haji H, Kisumku S, Thalib Al, Yahya SA: Control of bancroftian filariasis by integrating therapy with vector control using polystyrene beads in wet pit latrines. Trans R Soc Trop Med Hyg 1990, 84:709-714.

8. Maxwell CA, Mohammed K, Kisumku U, Curtis CF: Can vector control play a useful supplementary role against bancroftian filariasis? Bull World Health Organ 1999, 77:138-143.

9. Sasa M: Human Filariasis - A Global Survey of Epidemiology and Control Baltimore, Maryland: University Park Press; 1976.

10. Filariasis Research and Control in Eastern and Southern Africa. Edited by: Simonsen PE, Malecela MN, Michael E, Mackenzie CD. Denmark: DBL-Centre for Health Research and Development; 2008:.

11. Subra R: Biology and control of Culex pipiens quinquefasciatus with special reference to Africa. Insect Sci Applic 1981, 1:319-338.

12. Barr AR: Occurrence and distribution of the Culex pipiens complex. Bull World Health Organ 1967, 37:293-296.

13. Mattingly PF, Lloyd E, Rozenbool KL, Knight H, Laven FH, Drummond S, Christophers R, Shute PG: The Culex pipiens complex. Trans R Ent Soc Lond 1951, 102(Part 7):331-342.

14. Aders WM: Insects injurious to man and stock in Zanzibar. Bull Entomol Res 1917, 7:391-401.

15. World Health Organization: Progress report 2000-2009 and strategic plan 2010-2020 of the global programme to eliminate lymphatic filariasis: halfway towards eliminating lymphatic filariasis Geneva: WHO/HTM/NTD/PCT; 2010.

16. Bockarie MJ: Molecular xenomonitoring of lymphatic filariasis. Am J Trop Med Hyg 2007, 77:591-92

17. Bockarie MJ, Pedersen EM, White GB, Michael E: Role of vector control in the global program to eliminate lymphatic filariasis. Annu Rev Entomol 2009, 54:469-487.

18. Pedersen EM, Stolk WA, Laney SJ, Michael E: The role of monitoring mosquito infection in the Global Programme to Eliminate Lymphatic Filariasis. Trends Parasitol 2009, 25:319-327.

19. The President's Malaria Initiative: Country Profiles - Tanzania. FY 2007 Malaria Operational Plan (MOP) Tanzania. Tanzania.[http://www fightingmalaria.gov/]. 
20. World Health Organization: World Malaria Report 2010. Geneva; 2010 [http://www.who.int/malaria/world_malaria_report_2010/].

21. Matola YG, Mwita U, Masoud AE: Malaria in the Islands of Zanzibar and Pemba 11 years after the Suspension of a Malaria Eradication Programme. Cent Afr J Med 1984, 30:91-96.

22. Lines JD, Nassor NS: DDT resistance in Anopheles gambiae declines with mosquito age. Med Vet Entomol 1991, 5:261-265.

23. Curtis CF, Pasteur N: Organophosphate resistance in vector populations of the complex of Culex pipiens L. (Diptera:Culicidae). Bull Entomol Res 1981, 71:153-156.

24. Villani F, White GB, Curtis CF, Miles SJ: Inheritance and activity of some esterases associated with organophosphate resistance in mosquitoes of the complex of Culex pipiens L. (Diptera: Culicidae). Bull Entomol Res 1983, 73:153-170.

25. Curtis CF, Lines JD, Hill N: DDT resistance in An. gambiae s.s. from Zanzibar: Mosquito Studies at the London School of Hygiene and Tropical Medicine. Progress Report No 1983, 44:10-12.

26. Prapanthadara L, Hemingway J, Ketterman AJ: DDT-resistance in Anopheles gambiae (Diptera: culicidae) from Zanzibar, Tanzania, based on increased DDT-dehydrochlorinase activity of the glutathione Stransferases. Bull Entomol Res 1995, 85:267-274.

27. Ramzy RMR, Farid HA, Kamal IH, Ghada H, Ibrahim GH, Morsy ZS, Faris R, Weil GJ, Williams SA, Gad AM: A polymerase chain reaction-based assay for detection of Wuchereria bancrofti in human blood and Culex pipiens. Trans R Soc Trop Med Hyg 1997, 91:156-160

28. Smith $J$, Fonseca DM: Rapid assays for identification of members of the Culex (Culex) pipiens complex, their hybrids, and other sibling species (Diptera: Culicidae). Am J Trop Med Hyg 2004, 70:339-345.

29. Simon C, Frati F, Beckenbach A, Crespi B, Liu H, Flook P: Evolution, weighting, and phylogenetic utility of mitochondrial gene sequences and compilation of conserved polymerase chain reaction primers. Ann Entomol Soc Am 1994, 87:651-701.

30. Livak KJ: Organization and mapping of a sequence on the Drosophila melanogaster $X$ and $Y$ chromosomes that is transcribed during spermatogenesis. Genetics 1983, 107:611.

31. Wondji CS, Priyanka De Silva WA, Hemingway J, Ranson H, Parakrama Karunaratne SH: Characterization of knockdown resistance in DDT-and pyrethroid-resistant Culex quinquefasciatus populations from Sri Lanka. Trop Med Int Health 2008, 13:548-555.

32. Weill M, Fort P, Berthomieu A, Dubois MP, Pasteur N, Raymond M: A novel acetylcholinesterase gene in mosquitoes codes for the insecticide target and is non-homologous to the ace gene in Drosophila. Proc Royal Soc London Series B-Biol Sci 2002, 269:2007-2016.

33. Weill M, Malcolm C, Chandre F, Mogensen K, Berthomieu A, Marquine M, Raymond M: The unique mutation in ace-1 giving high insecticide resistance is easily detectable in mosquito vectors. Insect Molecular Biology 2004, 13:1-7.

34. World Health Organization: WHO position statement on integrated vector management to control malaria and lymphatic filariasis. Wkly Epidemiol Rec 2011, 86:121-127

35. Tatem AJ, Qiu Y, Smith DL, Sabot O, Ali AS, Moonen B: The use of mobile phone data for the estimation of the travel patterns and imported Plasmodium falciparum rates among Zanzibar residents. Malar J 2009, 8:287

36. Bhattarai A, Ali AS, Kachur SP, Mårtensson A, Abbas AK, Khatib R, AlMafazy AW, Ramsan M, Rotllant G, Gerstenmaier JF, Molteni F, Abdulla S, Montgomery SM, Kaneko A, Björkman A: Impact of artemisinin-based combination therapy and insecticide-treated nets on malaria burden in Zanzibar. PLoS Med 2007, 4:e309.

37. Beer N, Ali AS, de Savigny D, Al-Mafazy AW, Ramsan M, Abass AK, Omari RS, Björkman A, Källander K: System effectiveness of a targeted free mass distribution of long lasting insecticidal nets in Zanzibar. Tanzania Malar $J$ 2010, 9:173.

38. Ashton RA, Kyabayinze DJ, Opio T, Auma A, Edwards T, Matwale G, Onapa A, Brooker S, Kolaczinski JH: The impact of mass drug administration and long-lasting insecticidal nets distribution on Wuchereria bancrofti infection in humans and mosquitoes: an observational study in northern Uganda. Parasit Vectors 2011, 4:134.

39. Pedersen EM, Mukoko DA: Impact of insecticide-treated materials on filaria transmission by the various species of vector mosquito in Africa. Ann Trop Med Parasitol 2002, 96(Suppl 2):S91-S95.
40. Emukah E, Graves PM, Mosher AW, Rakers L, Miri E, Chidiebere N, Kenrick N, Josephine O, Njideka OT, Richards FO: Long lasting insecticidal nets alone can reduce transmission of lymphatic filariasis in south east Nigeria Washington: Abstract Book American Society of Tropical Medicine and Hygiene 58th Annual Meeting; 2009.

41. Bockarie MJ, Tavul L, Kastens W, Michael E, Kazura JW: Impact of untreated bednets on prevalence of Wuchereria bancrofti transmitted by Anopheles farauti in Papua New Guinea. Med Vet Entomol 2002, 16:116-119.

42. Webber RH: The natural decline of Wuchereria bancrofti infection in a vector control situation in the Solomon Islands. Trans R Soc Trop Med Hyg 1977, 71:396-400.

43. Webber RH: Eradication of Wuchereria bancrofti infection through vector control. Trans R Soc Trop Med Hyg 1979, 73:722-724.

44. Bang YH, Sabuni IB, Tonn RJ: Integrated control of urban mosquitoes in Dar es Salaam using community sanitation supplemented by larviciding. East Afr Med J 1975, 52:578-588.

45. Minjas JN: Control of Culex quinquefasciatus in pit latrines: reducing costs through selective larviciding. Trans R Soc Trop Med Hyg 1984, 78:847-848.

46. Charlwood JD: The control of Culex quinquefasciatus breeding in septic tanks using expanded polystyrene beads in southern Tanzania. Trans $R$ Soc Trop Med Hyg 1994, 88:380

47. Chavasse DC, Lines JD, Ichimori K, Majala AR, Minjas JN, Marijani J: Mosquito control in Dar es Salaam. II Impact of expanded polystyrene beads and pyripoxyfen treatment of breeding sites on Culex quinquefasciatus densities. Med Vet Entomol 1995, 9:147-154.

48. Curtis CF, Malecela-Lazaro M, Reuben R, Maxwell CA: Use of floating layers of polystyrene beads to control populations of the filaria vector Culex quinquefasciatus. Ann Trop Med Parasitol 2002, 96(Suppl 2):S97-104.

49. Curtis CF, Keto A, Ramji BD, losson I: Assessment of the impact of chlorpyrifos resistance in Culex quinquefasciatus on a control scheme. Insect Sci Applic 1984, 5:263-267.

50. Tungu P, Magesa S, Maxwell C, Malima R, Masue D, Sudi W, Myamba J, Pigeon O, Rowland M: Evaluation of PermaNet 3.0 a deltamethrin-PBO combination net against Anopheles gambiae and pyrethroid reistant Culex quinquefasciatus mosquitoes: an experimental hut trial in Tanzania. Malar J 2010, 9:21.

51. Khayrandish A, Wood RJ: A multiple basis for insecticide resisance in a strain of Culex quinquefasciatus (Diptera, Culicidae) from Muheza, Tanzania, studied as resistance declined. Bull Ent Res 1993, 83:75-86.

52. Ranson H, N'guessan R, Lines J, Moiroux N, Nkuni Z, Corbel V: Pyrethroid resistance in African anopheline mosquitoes: what are the implications for malaria control? Trends Parasitol 2011, 27:91-98, Epub 2010 Sep 16.

53. Corbel V, N'Guessan R, Brengues C, Chandre F, Djogbenou L, Martin T, Akogbéto M, Hougard JM, Rowland M: Multiple insecticide resistance mechanisms in Anopheles gambiae and Culex quinquefasciatus from Benin, West Africa. Acta Tropica 2007, 101:207-216.

54. Martinez-Torres D, Chevillon C, Brun-Barale A, Berge JB, Pasteur N, Pauron D: Voltage-dependent $\mathrm{Na}+$ channels in pyrethroid resistant Culex pipiens $\mathrm{L}$ mosquitoes. Pesticide Science 1998, 55:1012-1020.

55. Chen L, Zhong DB, Zhang DH, Shi LN, Zhou GF, Gong MQ, Zhou HY, Sun Y, Ma L, He J, Hong S, Zhou D, Xiong C, Chen C, Zou P, Zhu C, Yan G: Molecular Ecology of Pyrethroid Knockdown Resistance in Culex pipiens pallens Mosquitoes. Plos One 2010, 5:7.

56. Niranjan Reddy BP, Labbe P, Corbel V: Culex genome is not just another genome for comparative genomics. Parasit Vectors 2012, 5:63.

doi:10.1186/1756-3305-5-78

Cite this article as: Jones et al:: Insecticide resistance in Culex quinquefasciatus from Zanzibar: implications for vector control programmes. Parasites \& Vectors 2012 5:78. 